\title{
Association between Childhood Maltreatment and Suicidal Ideation and Suicide Attempts among Chinese Adolescents: The Moderating Role of Depressive Symptoms
}

\author{
Meiqian Gong ${ }^{\dagger}$, Sheng Zhang ${ }^{\dagger}$, Wenyan Li, Wanxin Wang, Ruipeng Wu, Lan Guo *, \\ and Ciyong $\mathrm{Lu} *$, \\ Department of Medical Statistics and Epidemiology, School of Public Health, Sun Yat-sen University, \\ Guangzhou 510080, China; gongmq@mail2.sysu.edu.cn (M.G.); zhangsh46@mail2.sysu.edu.cn (S.Z.); \\ liwy23@mail2.sysu.edu.cn (W.L.); wangwanx@mail2.sysu.edu.cn (W.W.); wurp5@mail2.sysu.edu.cn (R.W.) \\ * Correspondence: guolan3@mail.sysu.edu.cn (L.G.); luciyong@mail.sysu.edu.cn (C.L.); \\ Tel.: +86-20-87332477 (C.L.) \\ + These authors contributed equally to this work. \\ $\ddagger$ These authors contributed equally to this work.
}

Received: 23 July 2020; Accepted: 17 August 2020; Published: 19 August 2020

\begin{abstract}
Suicidal behavior is a major public health concern worldwide and has become the second-leading cause of death among adolescents. The purposes of this study were to investigate the associations between childhood maltreatment and suicidal behavior and to test whether depressive symptoms have moderating effects on these associations. A multistage stratified cluster randomized sampling method was adopted to collect data from 21,019 high school students in Guangdong Province, China. The prevalence of suicidal ideation and suicide attempts among Chinese adolescents were 18.2\% and 3.6\%, respectively. Physical abuse (adjusted odds ratios $(\mathrm{AOR})=1.35,95 \%$ confidence intervals $(\mathrm{CI})=1.32-1.38$ ), emotional abuse $(A O R=1.26,95 \% C I=1.25-1.28)$, sexual abuse $(A O R=1.25,95 \% C I=1.21-1.30)$, physical neglect $(\mathrm{AOR}=1.09,95 \% \mathrm{CI}=1.08-1.11)$, and emotional neglect $(\mathrm{AOR}=1.08,95 \% \mathrm{CI}=1.08-1.09)$ were all associated with an increased risk of suicidal ideation, and these associations were also found for suicide attempts. According to stratification analyses, physical abuse/emotional abuse/sexual abuse had a stronger effect on suicidal ideation and suicide attempts among students without depressive symptoms than among students with depressive symptoms. Childhood maltreatment was associated with an increased risk of suicidal ideation and suicide attempts in Chinese adolescents. Depressive symptoms play a moderating role in the association between childhood maltreatment and suicidal behaviors.
\end{abstract}

Keywords: suicidal ideation; suicidal attempts; childhood maltreatment; depressive symptoms; adolescents

\section{Introduction}

Suicidal behavior, including suicidal ideation, suicidal attempts, and completed suicide, threatens people's lives and the quality of life of survivors. More than 800,000 people die every year from suicide worldwide [1], and the sharp increase in suicidal deaths occurs among adolescents aged 15-19 years [2]. Notably, suicide has become the second-leading cause of death among adolescents [3]. According to a study, we learned that the prevalence rate of suicidal behaviors among United States students ranged from $6 \%$ to $25 \%$ and among Chinese students ranged from $2.7 \%$ to $45.1 \%$ [4]. Previous research also suggests that suicidal ideation and suicide attempts are predictors of suicide in adolescents [5] and that the timely identification of them can effectively reduce the incidence of completed suicide. 
Childhood abuse is a global phenomenon that affects millions of children worldwide [6], and it includes five types: emotional abuse, physical abuse, sexual abuse, emotional neglect, and physical neglect. According to a review that contains 244 publications worldwide and 551 prevalence rates for the different types of childhood abuse, we learned that the overall estimated prevalence was as follows: physical abuse (22.6\%), emotional abuse (36.3\%), sexual abuse (12.7\%), physical neglect $(16.3 \%)$, and emotional neglect (18.4\%) [6]. Compared with Western countries, Chinese parenting styles are more severe and have been generally accepted by Chinese people. A systematic review shows that $26.6 \%$ of children under the age of 18 in China suffer from physical abuse, $19.6 \%$ suffer from emotional abuse, $8.7 \%$ suffer from sexual abuse, and $26.0 \%$ suffer from neglect [7]. The interpersonal theory of suicide proposes that adverse experiences such as childhood maltreatment can form a state of adaptation to pain, can reduce the victim's fear of self-harm, and can eventually contribute to suicidal behavior [8]. A number of studies have suggested that childhood abuse is related to increased risk of suicidal behavior in adolescents [9-11].

Moreover, studies have reported that people who experienced childhood abuse have an increased risk of depressive symptoms [12-14]. A study has suggested that abused adolescents are at high risk of depressive symptoms [15]. In addition, the relationships between depressive symptoms and suicidal behavior have been extensively studied. Multiple studies have suggested that depressive symptoms promote suicidal behavior in young people $[16,17]$. To sum up, we can reasonably assume that depressive symptoms may play a moderating role in the association between childhood maltreatment and suicidal behavior among adolescents.

Childhood maltreatment has a far-reaching negative impact on the physical and mental development of individuals [18,19]. However, there are scarce studies on the impact of childhood abuse in China [7]. In addition, although many evidences have shown that childhood abuse is associated with suicidal behavior, the relationship and strength between different types of childhood maltreatment and suicidal behavior varies across countries and populations [20,21]. Moreover, the interaction between childhood abuse, depressive symptoms, and suicidal behavior remains controversial. For example, a study analyzed the interaction between childhood abuse and mental disorders, and its impacts on suicidal behavior and found that childhood abuse had a significant impact on suicidal behavior in the general population but not on individuals with mood disorders [20]. However, another study showed that the interaction terms of various types of childhood maltreatment and depression symptoms were not significantly related to suicide [22]. Finally, few studies have explored the potential moderating role of depressive symptoms in the association between childhood abuse and suicidal behavior in Chinese adolescents. Therefore, the purposes of this study were (1) to investigate the associations as well as the strengths between childhood maltreatment and suicidal behavior and (2) to test whether these associations and strengths vary with adolescents' depressive symptoms.

\section{Materials and Methods}

\subsection{Study Design and Participants}

This is a cross-sectional study, and the study participants are students in Guangdong Province in the 2018-2019 academic year. A multistage stratified cluster randomized sampling method was adopted. First, the regional economic development across Guangdong is relatively uneven. Therefore, according to the GDP per capita level in 2017, all cities in Guangdong were divided into three groups: high, medium, and low. Two cities were randomly selected from each level as representatives. Second, six junior high schools, four senior high schools, and two vocational high schools were randomly selected in each city. Third, two classes were randomly selected from each grade in each school. All students in the selected classes were invited to participate in the survey. A total of 21,019 students were invited to participate in our study, and 20,517 valid questionnaires were ultimately obtained, with a response rate of $97.6 \%$. Our self-report questionnaire was anonymous, and the students filled 
out the questionnaires only with the investigators but without the teachers. It took nearly three months to collect all the data.

\subsection{Ethical Statement}

The cross-sectional study of adolescents in Guangdong Province was ethically approved by the Sun Yat-sen University School of Public Health Institutional Review Board (Ethical Approval Number: 2012(20)). After the purpose and significance of the study had been fully explained, written informed consent was obtained from each student (aged 18 or above) or their parents (aged under 18).

\subsection{Measures}

\subsubsection{Suicidal Ideation and Suicidal Attempts}

The assessment of suicidal ideation and suicide attempts uses the following questions: "During the past year, how many times did you seriously consider attempting suicide?" for suicidal ideation and "During the past year, how many times did you actually attempt suicide?" for suicide attempts. Available answers were " 0 ", " 1 ", and "at least 2 times"; choosing " 1 " or "at least 2 times" represents suicidal ideation/suicide attempts [23].

\subsubsection{Childhood Maltreatment}

Childhood maltreatment was evaluated using the short form of the Childhood Trauma Questionnaire (CTQ-SF) in Chinese [24,25]. The CTQ-SF has good reliability and validity among the Chinese student population [26] and showed high internal consistency (Cronbach's alpha $=0.77$ ) [27]. In addition, it has been extensively used in a number of studies on Chinese adolescents [28,29].

The scale contains five subscales to assess five types of childhood maltreatment. Each subscale contains five questions, each question has 5 possible response options, and scores of 1-5 are given according to the selected options. The overall scale had scores ranging from 25 to 125 . The higher the scores, the more severe the childhood abuse.

\subsubsection{Depressive Symptoms}

The Chinese version of the Center for Epidemiology Scale for Depression (CES-D) was used to assess whether the respondents had depression symptoms. This Chinese version of the scale has been verified by scholars and is widely used in Chinese [30,31]. The scale showed high internal consistency among Chinese adolescents (Cronbach's alpha $=0.88$ ) [32]. This scale contains 20 items about depressive symptoms, and each item has four alternative answers; scores of 0-3 are given according to the selected answers. The total score of the scale is the sum of the scores of each item, with a minimum score of 0 and a maximum score of 60 . The higher the scores are, the more severe the depressive symptoms. In this study, a cutoff value of 28 was used to classify whether the subjects had depressive symptoms $[33,34]$.

\subsubsection{Covariates}

Factors associated with suicide or childhood abuse were taken into consideration [35-37]. Demographic factors included age, gender, and grade. Family-related factors included living arrangements, household socioeconomic status (HSS), and parental marital status. School-related factors included academic pressure, classmate relations, and teacher-classmate relations. Living arrangements were assessed by asking students who lived in their primary home (responses included "both biological parents", "only father or mother", or "other"). The answers to questions about the HSS (answers included "good", "average", or "poor"), parental marital status (answers included "harmonious", "often quarrel", or "separated or divorced"), academic pressure (answers included "above average", "average", and "below average"), and classmate relations and teacher-classmate relations (answers included "good", "average", or "poor") were all ranked based on the students' self-perception. Smoking and drinking were assessed by the following question: 
"Have you smoked at least one cigarette (or drunk alcohol) during your lifetime?" The response options were "yes" or "no".

\subsection{Statistical Analysis}

First, descriptive analyses for age, sex, childhood abuse, depressive symptoms, and suicidal behaviors were conducted. Continuous variables were described as the mean and standard deviation (SD), while categorical variables were expressed as the number and percentage (\%). Chi-square tests for categorical variables and t-tests and for continuous variables were used to compare the differences between groups.

Second, univariate logistic regression models were used to assess the association between different types of childhood maltreatment and depressive symptoms with suicidal ideation or suicide attempts. Then, multivariable logistic regression models that adjusted for variables that were significant at the 0.10 level in the univariate analysis or that were extensively reported in the literature were conducted to examine the independent relationship between childhood maltreatment and depressive symptoms with suicidal ideation or suicide attempts, and the adjusted odds ratios (AORs) and 95\% confidence intervals (CIs) were acquired.

Third, multivariable logistic regression models were used to test the interaction items between childhood maltreatment and depressive symptoms. If the association between the interaction item and suicidal ideation or suicide attempts was statistically significant, then the analyses stratified by depressive symptoms would be conducted to assess the associations of childhood maltreatment with suicidal ideation and suicide attempts. All statistical tests were two-sided, and the significance level was set at $p<0.05$. All statistical analyses were conducted using IBM SPSS Statistics 25.0 (IBM, Armonk, NY, USA).

\section{Results}

\subsection{Sample Characteristics of 20,517 Students}

A total of 20,517 students aged 11-20 were included in the analysis, of which $49.8 \%(10,221 / 20,517)$ were female students and $50.2 \%(10,296 / 20,517)$ were male students and the mean age was 15.0 (SD: 1.8$)$ years. In all samples, $3732(18.2 \%)$ students had suicidal ideation and $738(3.6 \%)$ had suicidal attempts in the past year. In addition, at the cutoff value of 28 on the CES-D scale, we detected that $11.0 \%$ of the students had depressive symptoms. Moreover, among students with suicidal ideation or suicidal attempts, the scores for all types of childhood maltreatment were higher than those of students without suicidal ideation or suicidal attempts $(p<0.001)$. These results are presented in Table 1.

\subsection{Association of Childhood Maltreatment and Depressive Symptoms with Suicidality}

In the unadjusted model, all five types of childhood abuse and depressive symptoms were significantly associated with suicidal ideation or suicide attempts $(p<0.001)$ (Model 1 in Table 2). After adjustments were made for covariates, our models showed that physical abuse ( $\mathrm{AOR}=1.35,95 \% \mathrm{CI}=1.32-1.38$ ), emotional abuse ( $\mathrm{AOR}=1.26,95 \% \mathrm{CI}=1.25-1.28)$, sexual abuse ( $\mathrm{AOR}=1.25,95 \% \mathrm{CI}=1.21-1.30)$, physical neglect ( $\mathrm{AOR}=1.09,95 \% \mathrm{CI}=1.08-1.11)$, emotional neglect $(\mathrm{AOR}=1.08,95 \% \mathrm{CI}=1.08-1.09)$, and depressive symptoms $(\mathrm{AOR}=6.77,95 \% \mathrm{CI}=6.07-7.54)$ were all associated with an increased risk of suicidal ideation. In addition, these associations were also found for suicide attempts (Model 2 in Table 2). 
Table 1. Sample characteristics of 20,517 students.

\begin{tabular}{|c|c|c|c|c|c|c|c|}
\hline \multirow{2}{*}{ Variable } & \multirow{2}{*}{ Total \# (\%) } & \multicolumn{3}{|c|}{ Suicidal Ideation } & \multicolumn{3}{|c|}{ Suicidal Attempts } \\
\hline & & Yes \# (\%) & No \# (\%) & $p$-Value * & Yes \# (\%) & No \# (\%) & $p$-Value \\
\hline Total & $20,517(100)$ & $3732(18.2)$ & $16,785(81.8)$ & & $738(3.6)$ & $19,779(96.4)$ & \\
\hline Age, mean (SD) & $15.0(1.8)$ & $14.9(1.7)$ & $15.0(1.8)$ & $<0.001$ & $14.7(1.6)$ & $15.0(1.8)$ & $<0.001$ \\
\hline \multicolumn{8}{|l|}{ Sex } \\
\hline Boy & $10,296(50.2)$ & $1342(13.0)$ & $8954(87.0)$ & $<0.001$ & $234(2.3)$ & $10,062(97.9)$ & $<0.001$ \\
\hline Girl & $10,221(49.8)$ & $2390(23.4)$ & 7831 (76.6) & & $504(4.9)$ & $9717(95.1)$ & \\
\hline \multicolumn{8}{|l|}{ Grade } \\
\hline 7 th & $3487(17.0)$ & $566(16.2)$ & $2921(83.8)$ & $<0.001$ & $110(3.2)$ & $3377(96.8)$ & $<0.001$ \\
\hline 8 th & 3405 (16.6) & $691(20.3)$ & $2714(79.7)$ & & $163(4.8)$ & $3242(95.2)$ & \\
\hline 9 th & 3317 (16.2) & 646 (19.5) & $2671(80.5)$ & & $126(3.8)$ & $3191(96.2)$ & \\
\hline 10th & $3798(18.5)$ & $771(20.3)$ & 3027 (79.7) & & $184(4.8)$ & $3614(95.2)$ & \\
\hline 11 th & 3598 (17.5) & $565(15.7)$ & $3033(84.3)$ & & $91(2.5)$ & $3507(97.5)$ & \\
\hline 12 th & $2912(14.2)$ & 493 (16.9) & $2419(83.1)$ & & $64(2.2)$ & $2848(97.8)$ & \\
\hline \multicolumn{8}{|l|}{ Living arrangement } \\
\hline Living with parents & $15,325(74.7)$ & $2576(16.8)$ & $12,749(83.2)$ & $<0.001$ & $485(3.2)$ & $14,840(96.8)$ & $<0.001$ \\
\hline Living with a single parent & $2677(13.0)$ & $674(25.2)$ & $2003(74.8)$ & & $151(5.6)$ & $2526(94.4)$ & \\
\hline Living with others & $2358(11.5)$ & $456(19.3)$ & $1902(80.7)$ & & $96(4.1)$ & $2262(95.9)$ & \\
\hline Missing data & $157(0.8)$ & NA & NA & & NA & NA & \\
\hline \multicolumn{8}{|l|}{ HSS } \\
\hline Above average & $6172(30.1)$ & $941(15.2)$ & $5231(84.8)$ & $<0.001$ & $179(2.9)$ & $5993(97.1)$ & $<0.001$ \\
\hline Average & $11,603(56.6)$ & $2135(18.4)$ & $9468(81.6)$ & & $430(3.7)$ & $11,173(96.3)$ & \\
\hline Below average & $2609(12.7)$ & $636(24.4)$ & 1973 (75.6) & & $121(4.6)$ & $2488(95.4)$ & \\
\hline Missing data & $133(0.6)$ & NA & NA & & NA & NA & \\
\hline \multicolumn{8}{|l|}{ Academic pressure } \\
\hline Below average & $4413(21.5)$ & $515(11.7)$ & $3898(88.3)$ & $<0.001$ & $110(2.5)$ & $4303(97.5)$ & $<0.001$ \\
\hline Average & $9318(45.4)$ & $1377(14.8)$ & 7941 (85.2) & & $273(2.9)$ & $9045(97.1)$ & \\
\hline Above average & $6653(32.4)$ & $1815(27.3)$ & $4838(72.7)$ & & $350(5.3)$ & $6303(94.7)$ & \\
\hline Missing data & $133(0.6)$ & NA & NA & & NA & NA & \\
\hline \multicolumn{8}{|l|}{ Parental marital status } \\
\hline Harmonious & $18,038(87.9)$ & $2940(16.3)$ & $15,098(83.7)$ & $<0.001$ & $553(3.1)$ & $17,485(96.9)$ & $<0.001$ \\
\hline Often quarrel & $586(2.9)$ & $265(45.2)$ & $321(54.8)$ & & $69(11.8)$ & $517(88.2)$ & \\
\hline Separated or divorced & $1745(8.5)$ & $506(29.0)$ & $1239(71.0)$ & & $114(6.5)$ & $1631(93.5)$ & \\
\hline Missing data & $148(0.7)$ & NA & NA & & NA & NA & \\
\hline
\end{tabular}


Table 1. Cont.

\begin{tabular}{|c|c|c|c|c|c|c|c|}
\hline \multirow{2}{*}{ Variable } & \multirow{2}{*}{ Total \# (\%) } & \multicolumn{3}{|c|}{ Suicidal Ideation } & \multicolumn{3}{|c|}{ Suicidal Attempts } \\
\hline & & Yes \# (\%) & No \# (\%) & $p$-Value * & Yes \# (\%) & No \# (\%) & $p$-Value * \\
\hline \multicolumn{8}{|l|}{ Classmate relations } \\
\hline Good & $16,699(81.4)$ & $2633(15.8)$ & $14,066(84.2)$ & $<0.001$ & $455(2.7)$ & $16,244(97.3)$ & $<0.001$ \\
\hline Average & $3391(16.5)$ & $944(27.8)$ & $2447(72.2)$ & & $234(6.9)$ & $3157(93.1)$ & \\
\hline Poor & $282(1.4)$ & $124(44.0)$ & $158(56.0)$ & & $42(14.9)$ & $240(85.1)$ & \\
\hline Missing data & $145(0.7)$ & NA & NA & & NA & NA & \\
\hline \multicolumn{8}{|l|}{ Teacher-classmate relations } \\
\hline Good & $14,179(69.2)$ & $2058(14.5)$ & $12,139(85.5)$ & $<0.001$ & $369(2.6)$ & $13,828(97.4)$ & $<0.001$ \\
\hline Average & $5716(27.9)$ & $1482(25.9)$ & $4234(74.1)$ & & $311(5.4)$ & $5405(94.6)$ & \\
\hline Poor & $376(1.8)$ & $148(39.4)$ & $228(60.6)$ & & $49(13.0)$ & $327(87.0)$ & \\
\hline Missing data & $228(1.1)$ & NA & NA & & NA & NA & \\
\hline \multicolumn{8}{|l|}{ Smoking } \\
\hline No & $18,481(90.1)$ & $3113(16.8)$ & $15,368(83.2)$ & $<0.001$ & $564(3.1)$ & $17,917(96.9)$ & $<0.001$ \\
\hline Yes & $1753(8.5)$ & $555(31.7)$ & $1198(68.3)$ & & $153(8.7)$ & $1600(91.3)$ & \\
\hline Missing data & $283(1.4)$ & NA & NA & & NA & NA & \\
\hline \multicolumn{8}{|l|}{ Drinking } \\
\hline No & $11,832(57.7)$ & $1472(12.4)$ & $10,360(87.6)$ & $<0.001$ & $242(2.0)$ & $11,590(98.0)$ & $<0.001$ \\
\hline Yes & $8379(40.8)$ & $2202(26.3)$ & $6177(73.7)$ & & $481(5.7)$ & $7898(94.3)$ & \\
\hline Missing data & $306(1.5)$ & NA & NA & & NA & NA & \\
\hline \multicolumn{8}{|l|}{ Depressive symptoms } \\
\hline No & $18,269(89.0)$ & $2361(12.9)$ & $15,908(87.1)$ & $<0.001$ & $346(1.9)$ & $17,923(98.1)$ & $<0.001$ \\
\hline Yes & $2248(11.0)$ & $1371(61.0)$ & $877(39.0)$ & & $392(17.4)$ & $1856(82.6)$ & \\
\hline CTQ scores of physical abuse ${ }^{a}$ & $5.7(1.6)$ & $6.6(2.4)$ & $5.5(1.2)$ & $<0.001$ & $7.4(3.3)$ & $5.6(1.4)$ & $<0.001$ \\
\hline CTQ scores of emotional abuse ${ }^{a}$ & $6.8(2.9)$ & $9.3(4.2)$ & $6.3(2.2)$ & $<0.001$ & $11.1(5.2)$ & $6.7(2.7)$ & $<0.001$ \\
\hline CTQ scores of sexual abuse ${ }^{a}$ & $5.2(1.1)$ & $5.6(1.6)$ & $5.2(0.9)$ & $<0.001$ & $5.8(2.2)$ & $5.2(1.0)$ & $<0.001$ \\
\hline CTQ scores of physical neglect ${ }^{a}$ & $7.2(2.8)$ & $8.1(3.2)$ & $7.0(2.7)$ & $<0.001$ & $9.0(3.7)$ & $7.2(2.8)$ & $<0.001$ \\
\hline CTQ scores of emotional neglect ${ }^{a}$ & $8.6(5.2)$ & $11.1(5.9)$ & $8.1(4.9)$ & $<0.001$ & $13.4(6.6)$ & $8.4(5.1)$ & $<0.001$ \\
\hline
\end{tabular}

Abbreviations: HSS, household socioeconomic status; CTQ, childhood trauma questionnaire; NA, not applicable or no data available; SD, standard deviation. \# Mean number. ${ }^{a}$ Data were presented as the mean (SD). * Chi-squared tests were used for categorical variables, and $t$ tests were used for age data and the CTQ scores data. 
Table 2. Association of childhood maltreatment and depressive symptoms with suicidality.

\begin{tabular}{|c|c|c|c|c|c|c|c|c|}
\hline \multirow{3}{*}{ Variable } & \multicolumn{4}{|c|}{ Models 1} & \multicolumn{4}{|c|}{ Models 2} \\
\hline & \multicolumn{2}{|c|}{ Suicidal Ideation } & \multicolumn{2}{|c|}{ Suicidal Attempts } & \multicolumn{2}{|c|}{ Suicidal Ideation } & \multicolumn{2}{|c|}{ Suicidal Attempts } \\
\hline & OR $(95 \% \mathrm{CI})$ & $p$-Value & OR $(95 \% C I)$ & $p$-Value & AOR $(95 \% \mathrm{CI})$ & $p$-Value & AOR $(95 \% \mathrm{CI})$ & $p$-Value \\
\hline Physical abuse * & $1.46(1.43-1.50)$ & $<0.001$ & $1.37(1.33-1.41)$ & $<0.001$ & $1.35(1.32-1.38)$ & $<0.001$ & $1.28(1.24-1.32)$ & $<0.001$ \\
\hline Emotional abuse * & $1.34(1.32-1.35)$ & $<0.001$ & $1.28(1.26-1.30)$ & $<0.001$ & $1.26(1.25-1.28)$ & $<0.001$ & $1.22(1.20-1.24)$ & $<0.001$ \\
\hline Sexual abuse * & $1.35(1.30-1.40)$ & $<0.001$ & $1.23(1.19-1.28)$ & $<0.001$ & $1.25(1.21-1.30)$ & $<0.001$ & $1.18(1.14-1.23)$ & $<0.001$ \\
\hline Physical neglect* & $1.12(1.11-1.14)$ & $<0.001$ & $1.20(1.18-1.23)$ & $<0.001$ & $1.09(1.08-1.11)$ & $<0.001$ & $1.15(1.12-1.17)$ & $<0.001$ \\
\hline Emotional neglect* & $1.10(1.09-1.11)$ & $<0.001$ & $1.13(1.12-1.14)$ & $<0.001$ & $1.08(1.08-1.09)$ & $<0.001$ & $1.11(1.09-1.12)$ & $<0.001$ \\
\hline \multicolumn{9}{|l|}{ Depressive symptoms } \\
\hline No & 1.00 & & 1.00 & & 1.00 & & 1.00 & \\
\hline Yes & $10.53(9.58-11.58)$ & $<0.001$ & $10.94(9.40-12.74)$ & $<0.001$ & $6.77(6.07-7.54)$ & $<0.001$ & $6.56(5.47-7.86)$ & $<0.001$ \\
\hline
\end{tabular}

Abbreviations: OR, odds ratio; CI, confidence interval; AOR, adjusted odds ratio. Model 1: univariate logistic regression, not adjusted for covariates. Model 2: adjusted for age, grade, gender, living arrangements, household socioeconomic status, academic pressure, parental marital status, relationships with classmates, relationships with teachers, smoking, and drinking. * For every 1 score increase in physical abuse, emotional abuse, sexual abuse, physical neglect, and emotional neglect. 


\title{
3.3. Associations of Interaction Items with Suicidal Ideation and Suicidal Attempts
}

As shown in Table 3, in our multivariable logistic regression models, the relationship between the interaction items (physical abuse/emotional abuse/sexual abuse and depressive symptoms) and suicidal ideation or suicide attempts was statistically significant (all $p<0.001)$. However, no statistical significance was found in the interaction items of physical neglect/emotional neglect and depressive symptoms with suicidal ideation or suicide attempts. In other words, depressive symptoms moderated the association between abuse (physical/emotional/sexual abuse) and suicidal ideation/suicide attempts, while the moderating effects were not significant in the association between neglect (physical neglect and emotional neglect) and suicidal ideation or suicide attempts.

Table 3. Associations of interaction items with suicidal ideation and suicidal attempts.

\begin{tabular}{|c|c|c|c|c|}
\hline \multirow{2}{*}{ Interaction Item } & \multicolumn{2}{|c|}{ Suicidal Ideation } & \multicolumn{2}{|c|}{ Suicidal Attempts } \\
\hline & AOR (95\% CI) & $p$-Value & AOR (95\% CI) & $p$-Value \\
\hline \multicolumn{5}{|l|}{ Depressive symptoms ${ }^{\text {a }}$} \\
\hline Physical abuse & $0.82(0.77-0.86)$ & $<0.001$ & $0.87(0.82-0.93)$ & $<0.001$ \\
\hline Emotional abuse & $0.90(0.87-0.93)$ & $<0.001$ & $0.92(0.89-0.95)$ & $<0.001$ \\
\hline Sexual abuse & $0.84(0.78-0.90)$ & $<0.001$ & $0.84(0.78-0.91)$ & $<0.001$ \\
\hline Physical neglect & $0.98(0.95-1.01)$ & 0.161 & $0.95(0.91-1.00)$ & 0.053 \\
\hline Emotional neglect & $0.99(0.97-1.00)$ & 0.115 & $0.98(0.95-1.00)$ & 0.087 \\
\hline
\end{tabular}

\begin{abstract}
Abbreviations: AOR, adjusted odds ratio; $\mathrm{CI}$, confidence interval. ${ }^{a}$ Each type of maltreatment, depressive symptom, and the interaction item between childhood maltreatment and depressive symptoms as well as age, grade, gender, living arrangements, household socioeconomic status, academic pressure, parental marital status, relationships with classmates, relationships with teachers, smoking, and drinking were simultaneously entered into the multivariable logistic regression models.
\end{abstract}

\subsection{Associations of Childhood Maltreatment and Suicidality Stratified by Depressive Symptoms}

After adjustments were made for the covariates, stratified analyses found that, among students with depressive symptoms, the association between sexual abuse and suicidal ideation (AOR $=1.05$, $95 \% \mathrm{CI}=0.99-1.11, p=0.083$ ) or suicide attempts (AOR $=1.05,95 \% \mathrm{CI}=1.00-1.12, p=0.072)$ was not statistically significant. However, among students without depressive symptoms, sexual abuse was significantly associated with suicidal ideation ( $\mathrm{AOR}=1.26,95 \% \mathrm{CI}=1.21-1.31, p<0.001$ ) and suicide attempts $(\mathrm{AOR}=1.24,95 \% \mathrm{CI}=1.17-1.31, p<0.001)$. In addition, both physical abuse and emotional abuse were associated with an increased risk of suicidal behavior among students with and without depressive symptoms. However, the associations between physical abuse/emotional abuse and suicidal behaviors were stronger among students without depressive symptoms than among those with depressive symptoms. The above results are summarized in Table 4. 
Table 4. Associations of childhood maltreatment and suicidality stratified by depressive symptoms.

\begin{tabular}{|c|c|c|c|c|c|c|c|c|}
\hline \multirow{3}{*}{ Variable } & \multicolumn{4}{|c|}{ With Depressive Symptoms } & \multicolumn{4}{|c|}{ Without Depressive Symptoms } \\
\hline & \multicolumn{2}{|c|}{ Suicidal Ideation } & \multicolumn{2}{|c|}{ Suicidal Attempts } & \multicolumn{2}{|c|}{ Suicidal Ideation } & \multicolumn{2}{|c|}{ Suicidal Attempts } \\
\hline & AOR $(95 \% \mathrm{CI})$ & $p$-Value & AOR $(95 \% \mathrm{CI})$ & $p$-Value & AOR $(95 \% \mathrm{CI})$ & $p$-Value & AOR $(95 \% \mathrm{CI})$ & $p$-Value \\
\hline Physical abuse * & $1.12(1.07-1.16)$ & $<0.001$ & $1.15(1.11-1.20)$ & $<0.001$ & $1.37(1.33-1.42)$ & $<0.001$ & $1.29(1.23-1.35)$ & $<0.001$ \\
\hline Emotional abuse * & $1.13(1.10-1.16)$ & $<0.001$ & $1.13(1.10-1.16)$ & $<0.001$ & $1.25(1.23-1.27)$ & $<0.001$ & $1.22(1.18-1.25)$ & $<0.001$ \\
\hline Sexual abuse ${ }^{*}$ & $1.05(0.99-1.11)$ & 0.083 & $1.05(1.00-1.12)$ & 0.072 & $1.26(1.21-1.31)$ & $<0.001$ & $1.24(1.17-1.31)$ & $<0.001$ \\
\hline Physical neglect* & $1.05(1.02-1.08)$ & 0.001 & $1.10(1.06-1.13)$ & $<0.001$ & $1.07(1.06-1.09)$ & $<0.001$ & $1.13(1.09-1.18)$ & $<0.001$ \\
\hline Emotional neglect* & $1.05(1.04-1.07)$ & $<0.001$ & $1.07(1.05-1.09)$ & $<0.001$ & $1.07(1.06-1.08)$ & $<0.001$ & $1.09(1.08-1.11)$ & $<0.001$ \\
\hline
\end{tabular}

Abbreviations: OR, odds ratio; CI, confidence interval; AOR, adjusted odds ratio. * For every 1 score increase in physical abuse, emotional abuse, sexual abuse, physical neglect, and emotional neglect. Note: All the models were adjusted for age, grade, gender, living arrangements, household socioeconomic status, academic pressure, parental marital status, relationships with classmates, relationships with teachers, smoking, and drinking. 


\section{Discussion}

There is a paucity of large-scale cross-sectional studies to explore whether depressive symptoms moderate the association between childhood abuse and suicidal behavior in Chinese students. Our study found that the average scores for each type of childhood maltreatment were as follows: physical abuse 5.7 (1.6), emotional abuse 6.8 (2.9), sexual abuse 5.2 (1.1), physical neglect 7.2 (2.8), and emotional neglect 8.6 (5.2). The scores for various types of childhood abuse are similar to those found in a 2014-2015 survey among adolescents in Chongqing, and in the above order of childhood abuse, the average scores were $5.6(1.7), 6.6(3.0), 5.5(1.8), 7.8$ (3.1), and 8.7 (5.4), respectively [29]. In addition, this study reported that the prevalence of suicidal ideation among adolescents was $18.2 \%$ and that the prevalence of suicide attempts was $3.6 \%$. The prevalence of suicidal ideation in the study was similar to that reported by the Youth Risk Behavior Surveillance System (YRBSS) in 2017 (17.2\%), but the prevalence of suicide attempts was lower than in the United States (7.4\%) [38]. The study also found that the prevalence of both suicidal ideation and suicide attempts was higher in girls than in boys (suicidal ideation: $13.0 \%$ for boys, $23.4 \%$ for girls; suicide attempts: $2.3 \%$ for boys and $4.9 \%$ for girls), which was consistent with the findings of many other studies [38,39].

This study analyzed the relationship between childhood abuse and suicidal behaviors and whether, in univariate logistic regression models or multivariable logistics regression models that controlled for covariates, all types of childhood abuse were related to increased risk of suicidality. These results are similar to those of many other studies [9,40,41]. However, our study found that, of the five types of maltreatment, physical abuse was most strongly associated with suicidal behavior, followed by emotional abuse. In contrast, another study argued that emotional abuse was the strongest predictor of suicide attempts, followed by physical abuse [20]. These differences may be related to the cultural background and traditional education methods of China and other countries. There are several possible explanations for the relationship between childhood abuse and suicidality. According to the Schematic Appraisals Model for Suicide (SAMS), adverse events in childhood can lead to increasing feelings of self-defeat and eventually to a choice of suicidality as a means of escape [42,43]. From the perspective of biological mechanisms, a previous study found that people who suffered from childhood abuse had a smaller prefrontal cortex volume [44], which was related to cognitive function [45], while cognitive impairment was related to suicidality [46].

In line with the findings of most studies $[16,47,48]$, our study also found that depressive symptoms contributed to suicidal behavior. In addition, our multivariable logistic regression shows that there are three interaction items (depressive symptoms* physical abuse/emotional abuse/sexual abuse) that were significant in relation to suicidal behaviors. Then, stratified analysis by depressive symptoms, the results indicated that the relation between sexual abuse and suicidal behaviors was found only among students without depressive symptoms. In addition, both physical abuse and emotional abuse were associated with an increased risk of suicidal behavior among participants with or without depressive symptoms. However, the associations between physical abuse/emotional abuse and suicidal behaviors were stronger among participants without depressive symptoms than among those with depressive symptoms. The above results suggest that depressive symptoms may moderate the relations between three types of childhood maltreatment (physical/emotional/sexual abuse) and suicidal behavior. Similarly, previous study has reported that childhood maltreatment has a significant effect on suicidal behavior in the general population but not in people with mood disorders [20]. Another study also proposed that "male depression" may play a moderating role in childhood maltreatment and suicidality [49]. However, the role of depressive symptoms in the association between childhood abuse and suicidality was not consistent in different studies. A study of elderly people over 60 years of age showed that the interaction terms of various types of childhood maltreatment and depression symptoms were not significantly related to suicide [22]. In addition, other studies have suggested that depression symptoms may play a mediating role in childhood abuse and suicidal behavior [28,50], but these studies did not rule out the association between the interaction terms of childhood abuse and depression symptoms, and suicidal behavior before the mediation analysis. Possible explanations for the moderating effect of depressive symptoms in 
our results are as follows. First, it is well known that depressive symptoms are important risk factors for suicide. Suicidal behavior may be more common in students with depressive symptoms than in those without. However, childhood maltreatment (distal risk factors) may be a more important factor in participants without depressive symptoms because, in participants with depressive symptoms, the effect of depressive symptoms on suicidality may be more important than the effect of childhood maltreatment. Second, after stratification by depressive symptoms, the sample size of individuals with depressive symptoms is relatively small and it may be more difficult to obtain statistically significant results.

Our study found that childhood maltreatment, depressive symptoms, and suicidal behavior remain serious problems among Chinese adolescents and should be of widespread concern. Based on our research results, we have the following suggestions. First, a national long-term monitoring system should be established to monitor suicidal behavior among Chinese adolescents. Second, schools should conduct mental health education regularly, and for students with depressive symptoms, timely identification and counseling should be performed. In addition, we suggested that parent-focused trainings specifically targeted at adolescent suicidal behavior should be carried out in schools. Third, parents should recognize the adverse effects of childhood maltreatment on their children and give them more physical or psychological care. Fourth, physicians should focus on the history of childhood maltreatment and depressive symptoms when treating suicidal adolescents.

There are some limitations in this study. First, the cross-sectional study design limits causal inference. Second, it is difficult to avoid potential bias when using a self-report questionnaire to collect data. Third, the study included only students who were not absent from class that day of the investigation. Fourth, students were only from Guangdong Province, so our findings should be carefully considered when applied to other regions.

\section{Conclusions}

Our study found that childhood maltreatment was associated with an increased risk of suicidal behavior in Chinese adolescents. Depressive symptoms moderate the association between three types of childhood abuse (physical/emotional/sexual abuse) and suicidal behaviors. Among students without depressive symptoms, physical/emotional/sexual abuse had a stronger effect on suicidal ideation and suicidal attempts. Our findings suggest that more attention should be paid to childhood maltreatment, depressive symptoms, and suicidal behaviors in Chinese adolescents and that early detection and intervention may contribute to the healthy development of adolescents.

Author Contributions: All the listed authors actively participated in the study: investigation, M.G., S.Z., W.L., W.W., and R.W.; project administration, C.L.; supervision, L.G. and C.L.; writing-original draft, M.G.; Writing-review and editing, S.Z., L.G., and C.L. All authors have read and agreed to the published version of the manuscript.

Funding: This work was supported by the Natural Science Foundation of Guangdong Province (grant number 2018A0303130331), by the Science Foundation for the Youth Scholars of Sun Yat-sen University (grant number 18ykpy15), by the National Natural Science Foundation of China (grant number 81761128030), and by the Guangdong Food and Drug Administration (grant number GZSW11175FT4055). The funder had no role in the design or conduct of the study; the collection, management, analysis, or interpretation of the data; the preparation, review, or approval of the manuscript; or the decision to submit the manuscript for publication.

Acknowledgments: The authors thank all of the participants in our study and sincerely acknowledge the technical support from the School of Public Health, Sun Yat-sen University.

Conflicts of Interest: The authors declare that they have no conflict of interest.

\section{References}

1. Bachmann, S. Epidemiology of Suicide and the Psychiatric Perspective. Int. J. Environ. Res. Public Health 2018, 15, 1425. [CrossRef] [PubMed]

2. Berger, G.E.; della Casa, A.; Pauli, D. Prevention and interventions for suicidal youth considerations for health professionionals in Switzerland. Ther. Umsch. 2015, 72, 619-632. [CrossRef] [PubMed] 
3. Patton, G.C.; Coffey, C.; Sawyer, S.M.; Viner, R.M.; Haller, D.M.; Bose, K.; Vos, T.; Ferguson, J.; Mathers, C.D. Global patterns of mortality in young people: A systematic analysis of population health data. Lancet 2009, 374, 881-892. [CrossRef]

4. Lew, B.; Osman, A.; Huen, J.M.Y.; Siau, C.S.; Abu Talib, M.; Jia, C.X.; Chan, C.M.H.; Leung, A.N.M. A comparison between American and Chinese college students on suicide -related behavior parameters. Int. J. Clin. Health Psychol. 2020, 20, 108-117. [CrossRef] [PubMed]

5. Cluver, L.; Orkin, M.; Boyes, M.E.; Sherr, L. Child and Adolescent Suicide Attempts, Suicidal Behavior, and Adverse Childhood Experiences in South Africa: A Prospective Study. J. Adolesc. Health 2015, 57, 52-59. [CrossRef] [PubMed]

6. Stoltenborgh, M.; Bakermans-Kranenburg, M.J.; Alink, L.R.A.; van IJzendoorn, M.H. The Prevalence of Child Maltreatment across the Globe: Review of a Series of Meta-Analyses. Child Abus. Rev. 2015, 24, 37-50. [CrossRef]

7. Fang, X.M.; Fry, D.A.; Ji, K.; Finkelhor, D.; Chen, J.Q.; Lannen, P.; Dunne, M.P. The burden of child maltreatment in China: A systematic review. Bull. World Health Organ. 2015, 93, 176C-185C. [CrossRef]

8. Van Orden, K.A.; Witte, T.K.; Cukrowicz, K.C.; Braithwaite, S.R.; Selby, E.A.; Joiner, T.E. The Interpersonal Theory of Suicide. Psychol. Rev. 2010, 117, 575-600. [CrossRef]

9. Miller, A.; Esposito-Smythers, C.; Weismoore, J.T.; Renshaw, K.D. The Relation Between Child Maltreatment and Adolescent Suicidal Behavior: A Systematic Review and Critical Examination of the Literature. Clin. Child Fam. Psychol. Rev. 2013, 16, 146-172. [CrossRef]

10. Gomez, S.H.; Tse, J.; Wang, Y.; Turner, B.; Millner, A.J.; Nock, M.K.; Dunn, E.C. Are there sensitive periods when child maltreatment substantially elevates suicide risk? Results from a nationally representative sample of adolescents. Depress. Anxiety 2017, 34, 734-741. [CrossRef]

11. Guo, L.; Wang, W.X.; Gao, X.; Huang, G.L.; Li, P.S.; Lu, C.Y. Associations of Childhood Maltreatment with Single and Multiple Suicide Attempts among Older Chinese Adolescents. J. Pediatr. 2018, 196, 244. [CrossRef]

12. Shapero, B.G.; Black, S.K.; Liu, R.T.; Klugman, J.; Bender, R.E.; Abramson, L.Y.; Alloy, L.B. Stressful Life Events and Depression Symptoms: The Effect of Childhood Emotional Abuse on Stress Reactivity. J. Clin. Psychol. 2014, 70, 209-223. [CrossRef] [PubMed]

13. Cohen, J.R.; Menon, S.V.; Shorey, R.C.; Le, V.D.; Temple, J.R. The distal consequences Of physical and emotional neglect in emerging adults: A person-centered, multi-wave, longitudinal study. Child Abus. Negl. 2017, 63, 151-161. [CrossRef]

14. Lindert, J.; von Ehrenstein, O.S.; Grashow, R.; Gal, G.; Braehler, E.; Weisskopf, M.G. Sexual and physical abuse in childhood is associated with depression and anxiety over the life course: Systematic review and meta-analysis. Int. J. Public Health 2014, 59, 359-372. [CrossRef]

15. De Bellis, M.D.; Nooner, K.B.; Scheid, J.M.; Cohen, J.A. Depression in Maltreated Children and Adolescents. Child Adolesc. Psychiatr. Clin. N. Am. 2019, 28, 289. [CrossRef]

16. Dvorak, R.D.; Lamis, D.A.; Malone, P.S. Alcohol use, depressive symptoms, and impulsivity as risk factors for suicide proneness among college students. J. Affect. Disord. 2013, 149, 326-334. [CrossRef]

17. Wang, Y.H.; Shi, Z.T.; Luo, Q.Y. Association of depressive symptoms and suicidal ideation among university students in China A systematic review and meta-analysis. Medicine 2017, 96, e6476. [CrossRef]

18. Gilbert, R.; Widom, C.S.; Browne, K.; Fergusson, D.; Webb, E.; Janson, S. Child Maltreatment 1 Burden consequences of child maltreatment in high-income countries. Lancet 2009, 373, 68-81. [CrossRef]

19. Gould, F.; Clarke, J.; Heim, C.; Harvey, P.D.; Majer, M.; Nemeroff, C.B. The effects of child abuse and neglect on cognitive functioning in adulthood. J. Psychiatr. Res. 2012, 46, 500-506. [CrossRef]

20. Liu, J.B.; Fang, Y.M.; Gong, J.B.; Cui, X.L.; Meng, T.T.; Xiao, B.; He, Y.Q.; Shen, Y.M.; Luo, X.R. Associations between suicidal behavior and childhood abuse and neglect: A meta-analysis. J. Affect. Disord. 2017, 220, 147-155. [CrossRef]

21. Zelazny, J.; Melhem, N.; Porta, G.; Biernesser, C.; Keilp, J.G.; Mann, J.J.; Oquendo, M.A.; Stanley, B.; Brent, D.A. Childhood Maltreatment, Neuropsychological Function and Suicidal Behavior. J. Child Psychol. Psychiatry 2019, 60, 1085-1093. [CrossRef]

22. Jardim, G.B.G.; Novelo, M.; Spanemberg, L.; von Gunten, A.; Engroff, P.; Nogueira, E.L.; Neto, A.C. Influence of childhood abuse and neglect subtypes on late-life suicide risk beyond depression. Child Abus. Negl. 2018, 80, 249-256. [CrossRef] 
23. Guo, L.; Xu, Y.; Deng, J.X.; Huang, J.H.; Huang, G.L.; Gao, X.; Wu, H.; Pan, S.Y.; Zhang, W.H.; Lu, C.Y. Association Between Nonmedical Use of Prescription Drugs and Suicidal Behavior Among Adolescents. JAMA Pediatr. 2016, 170, 971-978. [CrossRef]

24. Bernstein, D.P.; Fink, L.; Handelsman, L.; Foote, J.; Lovejoy, M.; Wenzel, K.; Sapareto, E.; Ruggiero, J. Initial Reliability and Validity of a New Retrospective Measure of Child-Abuse and Neglect. Am. J. Psychiatry 1994, 151, 1132-1136.

25. Bernstein, D.P.; Stein, J.A.; Newcomb, M.D.; Walker, E.; Pogge, D.; Ahluvalia, T.; Stokes, J.; Handelsman, L.; Medrano, M.; Desmond, D.; et al. Development and validation of a brief screening version of the Childhood Trauma Questionnaire. Child Abus. Negl. 2003, 27, 169-190. [CrossRef]

26. Shen, L.J.; Zhang, Y.L.; Liang, W.; Zhang, Y.L. Investigation of child maltreatment: Survey among junior school pupils in Henan province of China. Asia-Pac. Psychiatry 2015, 7, 85-90. [CrossRef]

27. Zhao, X.F.; Zhang, Y.L.; Li, L.F.; Zhou, Y.F.; Li, H.Z.; Yang, S.C. Reliability and validity of the Chinese version of childhood trauma Questionnaire. Zhongguo Linchuang Kangfu 2005, 9, 105-107. (In Chinese)

28. Tang, W.; Zhao, J.; Lu, Y.; Zha, Y.; Liu, H.; Sun, Y.; Zhang, J.; Yang, Y.; Xu, J. Suicidality, posttraumatic stress, and depressive reactions after earthquake and maltreatment: A cross-sectional survey of a random sample of 6132 chinese children and adolescents. J Affect. Disord. 2018, 232, 363-369. [CrossRef]

29. Lei, Y.L.; Xi, C.H.; Li, P.S.; Luo, M.; Wang, W.X.; Pan, S.Y.; Gao, X.; Xu, Y.; Huang, G.L.; Deng, X.Q.; et al. Association between childhood maltreatment and non-medical prescription opioid use among Chinese senior high school students: The moderating role of gender. J. Affect. Disord. 2018, 235, 421-427. [CrossRef]

30. Lee, S.W.; Stewart, S.M.; Byrne, B.M.; Wong, J.P.S.; Ho, S.Y.; Lee, P.W.H.; Lam, T.H. Factor structure of the Center for Epidemiological Studies Depression Scale in Hong Kong adolescents. J. Pers. Assess. 2008, 90, 175-184. [CrossRef]

31. Cheng, C.P.; Yen, C.F.; Ko, C.H.; Yen, J.Y. Factor structure of the center for epidemiologic studies depression scale in Taiwanese adolescents. Compr. Psychiatry 2012, 53, 299-307. [CrossRef]

32. Chen, Z.Y.; Yang, X.D.; Li, X.Y. Psychometric Features of CES-D in Chinese Adolescents. Chin. J. Clin. Psychol. 2009, 17, 443-445, 448. (In Chinese)

33. Guo, L.; Deng, J.X.; He, Y.; Deng, X.Q.; Huang, J.H.; Huang, G.L.; Gao, X.; Lu, C.Y. Prevalence and correlates of sleep disturbance and depressive symptoms among Chinese adolescents: A cross-sectional survey study. BMJ Open 2014, 4, e005517. [CrossRef]

34. Guo, L.; Xu, Y.; Deng, J.X.; Huang, J.H.; Huang, G.L.; Gao, X.; Li, P.S.; Wu, H.; Pan, S.Y.; Zhang, W.H.; et al. Association between sleep duration, suicidal ideation, and suicidal attempts among Chinese adolescents: The moderating role of depressive symptoms. J. Affect. Disord. 2017, 208, 355-362. [CrossRef]

35. King, C.A.; Merchant, C.R. Social and Interpersonal Factors Relating to Adolescent Suicidality: A Review of the Literature. Arch. Suicide Res. 2008, 12, 181-196. [CrossRef]

36. Joiner, T.E.; Sachs-Ericsson, N.J.; Wingate, L.R.; Brown, J.S.; Anestis, M.D.; Selby, E.A. Childhood physical and sexual abuse and lifetime number of suicide attempts: A persistent and theoretically important relationship. Behav. Res. Ther. 2007, 45, 539-547. [CrossRef]

37. Cano-Montalban, I.; Quevedo-Blasco, R. Sociodemographic Variables Most Associated with Suicidal Behaviour and Suicide Methods in Europe and America. A Systematic Review. Eur. J. Psychol. Appl. Legal Context 2018, 10, 15-25. [CrossRef]

38. Kann, L.; McManus, T.; Harris, W.A.; Shanklin, S.L.; Flint, K.H.; Queen, B.; Lowry, R.; Chyen, D.; Whittle, L.; Thornton, J.; et al. Youth Risk Behavior Surveillance-United States, 2017. Mmwr Surveill. Summ. 2018, 67, 1-114. [CrossRef]

39. Guo, L.; Luo, M.; Wang, W.X.; Xiao, D.; Xi, C.H.; Wang, T.; Zhao, M.J.; Zhang, W.H.; Lu, C.Y. Association between nonmedical use of opioids or sedatives and suicidal behavior among Chinese adolescents: An analysis of sex differences. Aust. N. Z. J. Psychiatry 2019, 53, 559-569. [CrossRef]

40. Anteghini, M.; Fonseca, H.; Ireland, M.; Blum, R.W. Health risk behaviors and associated risk and protective factors among Brazilian adolescents in Santos, Brazil. J. Adolesc. Health 2001, 28, 295-302. [CrossRef]

41. Angelakis, I.; Gillespie, E.L.; Panagioti, M. Childhood maltreatment and adult suicidality: A comprehensive systematic review with meta-analysis. Psychol. Med. 2019, 49, 1057-1078. [CrossRef]

42. Johnson, J.; Gooding, P.; Tarrier, N. Suicide risk in schizophrenia: Explanatory models and clinical implications, the schematic appraisal model of suicide (SAMS). Psychol. Psychother-Theory Res. Pract. 2008, 81, 55-77. [CrossRef] 
43. Williams, J.M.G.; Barnhofer, T.; Crane, C.; Beck, A.T. Problem solving deteriorates following mood challenge in formerly depressed patients with a history of suicidal ideation. J. Abnorm. Psychol. 2005, 114, 421-431. [CrossRef] [PubMed]

44. Tomoda, A.; Suzuki, H.; Rabi, K.; Sheu, Y.S.; Polcari, A.; Teicher, M.H. Reduced prefrontal cortical gray matter volume in young adults exposed to harsh corporal punishment. Neuroimage 2009, 47, T66-T71. [CrossRef]

45. Miller, E.K.; Cohen, J.D. An integrative theory of prefrontal cortex function. Annu. Rev. Neurosci. 2001, 24, 167-202. [CrossRef]

46. Olsson, P.; Wiktorsson, S.; Sacuiu, S.; Marlow, T.; Ostling, S.; Fassberg, M.M.; Skoog, I.; Waern, M. Cognitive Function in Older Suicide Attempters and a Population-Based Comparison Group. J. Geriatr. Psychiatry Neurol. 2016, 29, 133-141. [CrossRef] [PubMed]

47. Kisch, J.; Leino, E.V.; Silverman, M.M. Aspects of suicidal behavior, depression, and treatment in college students: Results from the spring 2000 National College Health Assessment Survey. Suicide Life-Threat. Behav. 2005, 35, 3-13. [CrossRef] [PubMed]

48. Wilcox, H.C.; Arria, A.M.; Caldeira, K.M.; Vincent, K.B.; Pinchevsky, G.M.; O'Grady, K.E. Prevalence and predictors of persistent suicide ideation, plans, and attempts during college. J. Affect. Disord. 2010, 127, 287-294. [CrossRef]

49. Pompili, M.; Innamorati, M.; Lamis, D.A.; Erbuto, D.; Venturini, P.; Ricci, F.; Serafini, G.; Amore, M.; Girardi, P. The associations among childhood maltreatment, "male depression" and suicide risk in psychiatric patients. Psychiatry Res. 2014, 220, 571-578. [CrossRef]

50. Miller, A.B.; Adams, L.M.; Esposito-Smythers, C.; Thompson, R.; Proctor, L.J. Parents and friendships: A longitudinal examination of interpersonal mediators of the relationship between child maltreatment and suicidal ideation. Psychiatry Res. 2014, 220, 998-1006. [CrossRef]

(C) 2020 by the authors. Licensee MDPI, Basel, Switzerland. This article is an open access article distributed under the terms and conditions of the Creative Commons Attribution (CC BY) license (http://creativecommons.org/licenses/by/4.0/). 